\title{
Fe-Mg zoning in olivine during rapid growth: kinetic effects are small, zoning nearly flatlines
}

\author{
THOMAS SHEA ${ }^{1}$, AdRIEN MOUREY ${ }^{1}$ \\ 1 Dept. of Earth Sciences, University of Hawai' $i$ at Mānoa
}

$\mathrm{Fe}-\mathrm{Mg}$ in olivine is widely used to track the evolution of mafic magmas and to calculate magma temperatures. Zoning in Fe-Mg is also exploited to determine magma mixing-toeruption timescales using diffusion chronometry. The technique relies partly on the assumption that gradual zoning is initially absent. The classic view, however, is that strong zoning can also develop during crystallization, as both olivine and melt become more Mg-poor. Olivine is now known to crystallize rapidly under even moderate conditions of undercooling, raising the question of whether kinetic effects (formation of boundary layers) can influence their composition and zoning [1].

Crystallization experiments at 1 atm were used to determine whether zoning develops during olivine growth, and whether disequilibrium processes affect magma temperatures calculated from olivine/melt equilibrium. A Kîlauea basalt was heated to superliquidus conditions $\left(1290^{\circ} \mathrm{C}\right)$ for $24 \mathrm{~h}$, and cooled to final temperatures corresponding to undercoolings of $10-100^{\circ} \mathrm{C}$. Charges were left to crystallize for $20 \mathrm{~min}$ to 96 hours and then quenched.

Boundary layers depleted in $\mathrm{Mg}$ are prominent at high undercooling $\left(60-100^{\circ} \mathrm{C}\right)$, but do not affect $\mathrm{Fe}-\mathrm{Mg}$ partitioning significantly. The olivine/melt Fe-Mg distribution coefficient is $\mathrm{K}_{\mathrm{D}}=0.325 \pm 0.006$ irrespective of undercooling or experiment duration. For longer runs that have reached a near-equilibrium state, glass $\mathrm{MgO}$ temperatures using [2] match run temperatures to better than $10^{\circ} \mathrm{C}$. Olivine compositions vary slightly within a given charge $(\leq 0.5 \mathrm{~mol} . \%$ Fo), and show only very minor Fe-Mg zoning ( $0.8 \mathrm{~mol} . \%$ Fo maximum along a single transect).

The lack of crystallization-induced zoning in Fe-Mg during olivine growth is good news for diffusion modeling but has to be considered in the context of crystal growth in magma reservoirs: numerical models of olivine crystallization show that the final amplitude of zoning depends on the number density of crystals overgrown for a given amount of undercooling. Our view of how magmas crystallize after a perturbation (one crystal forming after the other or all at the same time) ultimately dictates the mineral zoning record inherited from growth.

[1] Mourey \& Shea (2019) Frontiers Earth Sci 7, 300.

[2] Montierth et al. (1995) AGU Geophys Mono Ser, 207-217 